\title{
COMMENTARY
}

\section{Direct and Indirect Effects of Restrictive Immigration Policies on Pharmacy Education}

\author{
T. Joseph Mattingly II, PharmD, MBA, PhD, , ${ }^{\text {ab }}$ Shannon Weathers, $\mathrm{BS}^{\mathrm{a}}$ \\ ${ }^{a}$ University of Maryland, School of Pharmacy, Baltimore, Maryland \\ ${ }^{\mathrm{b}}$ Editorial Board Member, American Journal of Pharmaceutical Education, Arlington, Virginia
}

Corresponding Author: Joey Mattingly, University of Maryland, School of Pharmacy, 220 Arch Street, $12^{\text {th }}$ Floor, Baltimore, Maryland 21201. Tel: 410-706-8068; Email: jmattingly@rx.umaryland.edu.

Submitted December 29, 2020; accepted January 27, 2021; ePublished January 2021

Keywords: immigration; cultural competency; policy; international students; international faculty

United States (US) immigration policy and enforcement has experienced many ebbs and flows over our 244-year history as an independent nation, with policies either supporting or opposing the influx of new citizens at different stages of development. ${ }^{1}$ No political party can claim the proverbial "high ground" when immigration policy is viewed through a greater historical lens, but the Trump Administration campaigned on a hardline anti-immigrant platform and effectively executed several actions to restrict immigration into the US throughout his term in office. ${ }^{2}$ The nonpartisan Migration Policy Institute (MPI) has cataloged more than 400 executive actions under the Trump Administration effectively reshaping the US immigration system including actions on border protection, asylum case administration, immigration courts, and visa processes. ${ }^{3}$ While immigration policy changes in the US have broad implications on the economy, culture, and everyday life of millions of people, leaders in pharmacy education may not always connect these larger policy actions to the specific needs of our more focused pharmacy education stakeholders (students, faculty, staff, etc.). However, when Immigration and Customs Enforcement (ICE) announced this past July that students who were enrolled in schools that were shifting to onlineonly education due to the coronavirus disease 2019 (COVID-19) pandemic would not be eligible to retain their student visas and could be subject to deportation procedures unless they were attending at least one in-person class - immigration policy became a major priority for higher education leaders. ${ }^{4}$ While this rule was revoked shortly after, this action and the preceding pattern of immigration restriction raises concerns for those who are involved in pharmacy education and brings about the question of how future immigration policies could impact pharmacy schools. In this commentary, we provide an overview of potential direct and indirect effects of more restrictive immigration policies on the system of pharmacy education within and outside the US.

\section{Direct Impact}

Recruitment and Retention of International Students

The most immediate direct impact of restrictive measures for immigration involves decreasing the number of international students. A reduction in international student enrollment could be explicitly due to policy-based restrictions on who may legally enter the US as well as through a lower demand from these students who may seek to pursue their education elsewhere to avoid potential risk. The total number of reported pharmacy student applications received from nonUS residents has declined from 3,528 in 2017 to 2,788 in 2019. ${ }^{5}$ While this decline in non-US resident applications is likely occurring for a myriad of reasons (eg, less demand to be a pharmacist as total applications are down across the board), the temporality of the decline with the anti-immigrant rhetoric at a national level may be concerning. A decline in non-US applications in 2020 may also be expected as a result of COVID-19, making it difficult to assess the true impact of restrictive immigration policies independent of the global pandemic. However, it would be reasonable to expect similar dissuasion for international PharmD program applicants in the same way that fewer non-US-born medical graduates are choosing to participate in the National Resident Matching Program. ${ }^{6}$

Following graduation, non-US-born pharmacists may or may not stay in the US to practice pharmacy. More restrictive immigration policies may discourage these pharmacists from remaining in the US. Whether this effect is viewed as positive or negative may depend on the stakeholder perspective. From the perspective of US-born pharmacists, this could mean less competition for pharmacist jobs and have some positive implications for those graduates fortunate to have been born in the US. In terms of seeking post-PharmD training, non-US-born graduates have historically faced additional costs and administrative hurdles related to the visa process compared to their US-born colleagues making it more difficult to 
remain in the US. ${ }^{7}$ From the perspective of employers or post-graduate training programs seeking the most talented candidates, more restrictive immigration policies limit the pool. From a patient care or public health perspective, retaining these graduates may have greater implications on health disparities within the US that we will describe in more detail as an indirect effect later in the paper. ${ }^{8-10}$

\section{Recruitment and Retention of International Faculty}

Another direct impact involves the potential reduction in the number of international faculty employed by US schools of pharmacy. The accomplishments of foreign-born pharmacy faculty can be observed across all aspects of pharmacy education including research, clinical practice, education, and service to the profession. Economists have estimated that a college graduate immigrant contributes at least twice as much to patenting as compared to US-born counterparts, as highly-skilled immigrants in science, technology, engineering, and mathematics (STEM) are often sought after and recruited to the US. ${ }^{11}$

In addition to recruiting disadvantages for US schools wanting to attract brilliant non-US scientists, restrictive immigration policies may make it more difficult for US schools to retain top faculty who are currently on visas. Universities outside the US in countries with more relaxed immigration and travel policies may use these circumstances to recruit successful faculty away from US schools. Losing top non-US researchers would not only reduce pharmacy school scholarship potential (grants, publications, etc.), it would further reduce the ability for US and non-US students to train under these high-performing researchers. Many students rely on the faculty at their school to assist them with finding research opportunities, clinical opportunities, and internships, and having fewer faculty members performing these roles will negatively impact the ability of students to gain practice and professional growth before graduation. When also considering that international faculty members could be prime candidates to act as mentors to international students, a lack of non-US-born faculty members means that there will be fewer potential mentors for international students that understand the context of the students' backgrounds and may be better equipped to help guide these students in a possibly unfamiliar environment. $^{12}$

\section{Negative Effects on Cultural Competency Outcomes}

The education of pharmacy students on cultural competency and sensitivity is an integral part of pharmacy school curriculums and is explicitly reviewed as a part of the American Council on Pharmaceutical Education (ACPE) accrediting standards. ${ }^{13}$ The American College of Clinical Pharmacy's (ACCP) Task Force on Cultural Competency developed a series of white papers in the early 2000s describing cultural competency for health professionals should be viewed as a continuous process undertaken to ensure care is delivered in an appropriate manner among diverse populations. ${ }^{14}$ Further, the task force specifies that becoming culturally competent also requires a "conscious effort to reduce any ethnocentric biases" one may have. ${ }^{14}$ In other words, our students must demonstrate that they do not believe any one culture to be superior to another. Diversity throughout the student body, faculty, and staff encourages an environment that is not "culturally repetitive" and may improve a student's ability to communicate, empathize, and provide care to patients regardless of their background. ${ }^{12}$ Fewer non-US-born students may directly harm schools' abilities to provide this culturally rich environment for student development which has negative implications that may be directly observed during accreditation.

\section{Indirect Impact}

\section{Reduced International Opportunities for US-Born Students}

While direct effects of restrictive immigration policies are easier to quantify and potentially assess, indirect effects on pharmacy education may be more challenging to observe but may still be necessary to determine the full positive and negative implications of such policies. Restricting the educational opportunities within the US for non-US-born students based in other countries also introduces the possibility that, eventually, many countries will be less inclined to permit USborn students from seeking educational opportunities in their respective countries. Many pharmacy schools offer their students the chance to complete rotations at international sites as a part of reciprocal agreements between schools. For example, the University of Maryland School of Pharmacy offers international rotation opportunities for many different countries, including Egypt, India, Zambia, Peru, and Thailand. An unintended consequence of restrictive immigration policies within the US could simply manifest through reactionary anti-US policies as international relations deteriorate.

\section{Impact on Patient Care}

One potential area not commonly discussed during immigration policy debates involves the care for US patients. The US currently relies on a significant proportion of non-US-born and noncitizen health professionals to deliver care to its citizens. ${ }^{15}$ Approximately 1 in 5 pharmacists practicing in the US were not born in the US and another $4 \%$ are noncitizens. ${ }^{15}$ 
While we discussed the direct impact of reduced immigration on pharmacy school admissions and faculty, a significant reduction in the number of non-US-born practitioners would have downstream effects on care delivery. A recent crosssectional analysis of international medical graduates in the US physician workforce from 2009-2018 reported a directional shift in applications from Muslim-majority countries (increasing applications from 2009-2015, decreasing from 2016-2018) providing evidence that suggest specific anti-immigration policies could play a role in physician workforce dynamics. ${ }^{16}$ For pharmacy schools who consider advancing patient care or improving population health a critical part of their missions, potential impacts on patient care through workforce disruption should also be a concern.

The direct impact related to the cultural competency education for students described previously could exacerbate the effects on patient care. Students typically have more cross-racial and cross-cultural interactions in college and professional school compared to their K-12 experiences, so a highly diverse pharmacy school student body can greatly increase the opportunity for exposure to different cultures. ${ }^{17}$ In a survey of 24,657 medical school graduates, students enrolled in medical schools with highly diverse student bodies rated themselves as having higher self-perceived cultural competency and also felt they were more prepared to care for patients of other cultural backgrounds. ${ }^{18}$ Immigration policies that potentially limit the cultural diversity of pharmacy school enrollment may further diminish the care ultimately provided to a multicultural US population.

\section{Increased Health Disparity}

As previously mentioned, non-US-born practitioners disproportionately practice in underserved areas, providing more complexity to the health care workforce debate and potential indirect effects on care delivery to socioeconomically disadvantaged patients. ${ }^{8-10}$ During times of severe pharmacist shortages in the US, US-based retail chains and other major pharmacist employers recruited noncitizen pharmacists with visa sponsorship opportunities to help meet the demand. ${ }^{19}$ While the supply of pharmacists has stabilized, pockets of low resourced areas may still have needs that could be impeded by immigration restrictions. Additionally, damaging our international relationships with divisive rhetoric may hurt our ability to "go back to the well" the next time the US experiences a major pharmacist shortage.

\section{Call to Action}

Pharmacy education leaders may not typically prioritize advocacy efforts related to immigration policies as many of the policies implemented throughout the history of the US may have not been directly tied to higher education. However, both the anti-immigrant rhetoric and the proposed executive order specific to our non-US-born students taking remote classes during a global pandemic should be major causes for concern for our profession. We believe it is time for the Association to convene a task force or group of engaged leaders to focus specifically on the issue of US immigration policy and pharmacy education.

We aimed to highlight a few direct and indirect effects of more restrictive immigration policies, but we suspect that this article merely scratches the surface on this issue. Additionally, one's personal opinions related to immigration policy may bias the direction of each effect and so we recommend a multi-stakeholder approach to discuss this complex issue. When considering these different impacts, clearly defining the stakeholder perspective (student, faculty, staff, graduate, patient, society, etc.) is critical for any such policy evaluation. We also encourage the Association to engage with nonpartisan groups, such as the MPI, who have more direct experience with immigration policy to understand the historical context to provide guidance on how pharmacy leaders advocate on these issues effectively.

\section{REFERENCES}

1. National Academies of Sciences, Engineering and M. The Integration of Immigrants into American Society. Washington, DC: National Academies Press; 2015. doi:10.17226/21746

2. McCaskill ND. Trump promises wall and massive deportation program. Politico. https://www.politico.com/story/2016/08/donald-trump-immigration-address-arizona-227612. Published August 31, 2016. Accessed December 23, 2020.

3. Pierce S, Bolter J. Dismantling and Reconstructing the U.S. Immigration System: A Catalog of Changes under the Trump Presidency. Migration Policy Institute. https://www.migrationpolicy.org/research/us-immigration-systemchanges-trump-presidency. Published 2020. Accessed December 23, 2020.

4. Hansen C. Foreign Students Attending Schools That Operate Online-Only This Fall Will Be Barred From the U.S. U.S. News. https://www.usnews.com/news/national-news/articles/2020-07-06/foreign-students-attending-schoolsthat-operate-online-only-this-fall-will-be-barred-from-the-us. Published July 6, 2020. Accessed December 23, 2020.

5. American Association of Colleges of Pharmacy. Student Applications, Enrollments and Degrees Conferred 
Reports. https://www.aacp.org/research/institutional-research/student-applications-enrollments-and-degreesconferred. Published 2020. Accessed December 29, 2020.

6. Radabaugh CL, Welcher CM, Skochelak SE. Long-term Potential Implications of Immigration Barriers for Medical Education. J Am Med Assoc. 2019;321(8):741-742. doi:10.1001/jama.2019.0231

7. Traynor K. Non-U.S. pharmacists face residency hurdles. Am J Heal Pharm. 2012. doi:10.2146/news120020

8. Khullar D, Blumenthal DM, Olenski AR, Jena AB. U.S. immigration policy and American medical research: The scientific contributions of foreign medical graduates. Ann Intern Med. 2017;167(8):584-586. doi:10.7326/M171304

9. Pinsky WW. The importance of international medical graduates in the United States. Ann Intern Med. 2017;166(11):840-841. doi:10.7326/M17-0505

10. Ranasinghe PD. International medical graduates in the US physician workforce. J Am Osteopath Assoc. 2015;115(4):236-241. doi:10.7556/jaoa.2015.047

11. Hunt J, Gauthier-Loiselle M. How much does immigration boost innovation? Am Econ J Macroecon. 2010;2(2):31-56. doi:10.1257/mac.2.2.31

12. Chisholm MA. Diversity: A missing link to professionalism. Am J Pharm Educ. 2004;68(5):Article 120. doi:10.5688/aj6805120

13. Accreditation Council for Pharmacy Education. Accreditation Standards and Key Elements for the Professional Program in Pharmacy Leading to the Doctor of Pharmacy Degree ("Standards 2016"). https://www.acpeaccredit.org/pharmd-program-accreditation/. Published 2015. Accessed June 21, 2018.

14. O'Connell MB, Korner EJ, Rickles NM, Sias JJ. Cultural Competency in Health Care and Its Implications for Pharmacy: Part 1. Overview of key concepts in multicultural health care. Pharmacotherapy. 2007;27(7):10621079. doi:10.1592/phco.27.7.1062

15. Patel YM, Ly DP, Hicks T, Jena AB. Proportion of Non-US-Born and Noncitizen Health Care Professionals in the United States in 2016. J Am Med Assoc. 2018;320(21):2265-2267. doi:10.1001/jama.2018.14270

16. Boulet JR, Duvivier RJ, Pinsky WW. Prevalence of International Medical Graduates From Muslim-Majority Nations in the US Physician Workforce From 2009 to 2019. JAMA Netw open. 2020;3(7):e209418. doi:10.1001/jamanetworkopen.2020.9418

17. Whitla DK, Orfield G, Silen W, Teperow C, Howard C, Reede J. Educational benefits of diversity in medical school: A survey of students. Acad Med. 2003;78(5):460-466. doi:10.1097/00001888-200305000-00007

18. Saha S, Guiton G, Wimmers PF, Wilkerson LA. Student body racial and ethnic composition and diversity-related outcomes in US medical schools. J Am Med Assoc. 2008;300(10):1135-1145. doi:10.1001/jama.300.10.1135

19. U.S. Department of Health and Human Services. The Pharmacist Workforce: A Study of the Supply and Demand for Pharmacists. https://www.ihrp.uic.edu/files/Pharmacists Workforce.pdf. Published 2000. Accessed December $28,2020$. 